\title{
Safety in the Public Health Laboratory
}

\author{
E. B. M. COOK, M.A.
}

$\mathbf{R}^{\mathrm{n}}$ ECOGNIZING the endogenous hazards of public health laboratory procedures, which often involve contact with disease-producing agents, the Texas State Department of Health laboratory section has established a "watchdog" committee on laboratory safety. Its duties are to survey work hazards and accidents and to make recommendations for remedial action. The committee is made up of the supervisors of the three laboratory divisions. Laboratory-acquired infections have received major attention, but other hazards of the laboratory environment have also been studied. Based on committee recommendations, a standard form for reporting laboratory accidents and another for reporting laboratory exposure to or infection with pathogens have been adopted, and an employee immunization program and recording system have been instituted. Based on findings of hazard surveys, several changes in workroom and passageway design have been recommended.

\section{Survey Results}

The first hazard and infection survey was made in 1950 to provide information for the Sulkin and Pike questionnaire on laboratoryacquired infections (1). Records were available only back to 1930 . The second survey was made in 1956, about 2 years before the laboratory moved into new quarters. In these surveys 20 laboratory-acquired infections and 1 infection, rabies, contracted in related fieldwork

Mrs. Cook is principal immunologist, supervisor of the biologics production division, and chairman of the committee on laboratory safety, laboratory section, Texas State Department of Health. Her paper is based on one presented at the Tenth Annual Conference on Diseases in Nature Transmissible to Man, March 17, 1960, in Austin, Tex. were tabulated for the period 1930-56. The rabies infection, a fatal case, occurred in an entomologist from the laboratory who was engaged in bat rabies investigations (2). He and his associates had banded some 10,000 bats in connection with migration studies. Data on these infections and two others that occurred in 1957 and 1958 before the move into new quarters are summarized in the table.

The laboratory-acquired infections included two cases of an unusual infection caused by a bat salivary gland virus. The bats were autopsied and the brain and salivary gland tissues ground in glycerine-saline and injected intracranially into mice. In addition to recovering several strains of bat rabies virus, several isolations were made of an unknown salivary gland virus, which was later identified as antigenically related to the arthropod-borne group B viruses $(3,4)$.

One worker engaged in the bat-screening project was ill for about a week with symptoms of dizziness, paresthesia, and general malaise. Blood specimens showed a rise in the complement-fixing titer for the salivary gland isolates and neutralization index change from 0 to 1:1,000. The other worker had a less apparent illness with some malaise but no distinct symptoms; blood specimens, however, showed a complement-fixing titer rise and a neutralization index change from 0 to $1: 80$ for the salivary gland virus.

Also of particular interest were six cases of typhus fever probably due to contact with aerosols resulting from processing typhus vaccine. Of the six cases, only two persons were actually handling the agent; the others merely worked in the same area. The one severe allergic pulmonary reaction was thought to be due to direct inhalation of hen's eggshell dust.

The 1956 survey also revealed a number of 
Summary of laboratory-acquired infections in Texas State Department of Health, 1930-60 ${ }^{1}$

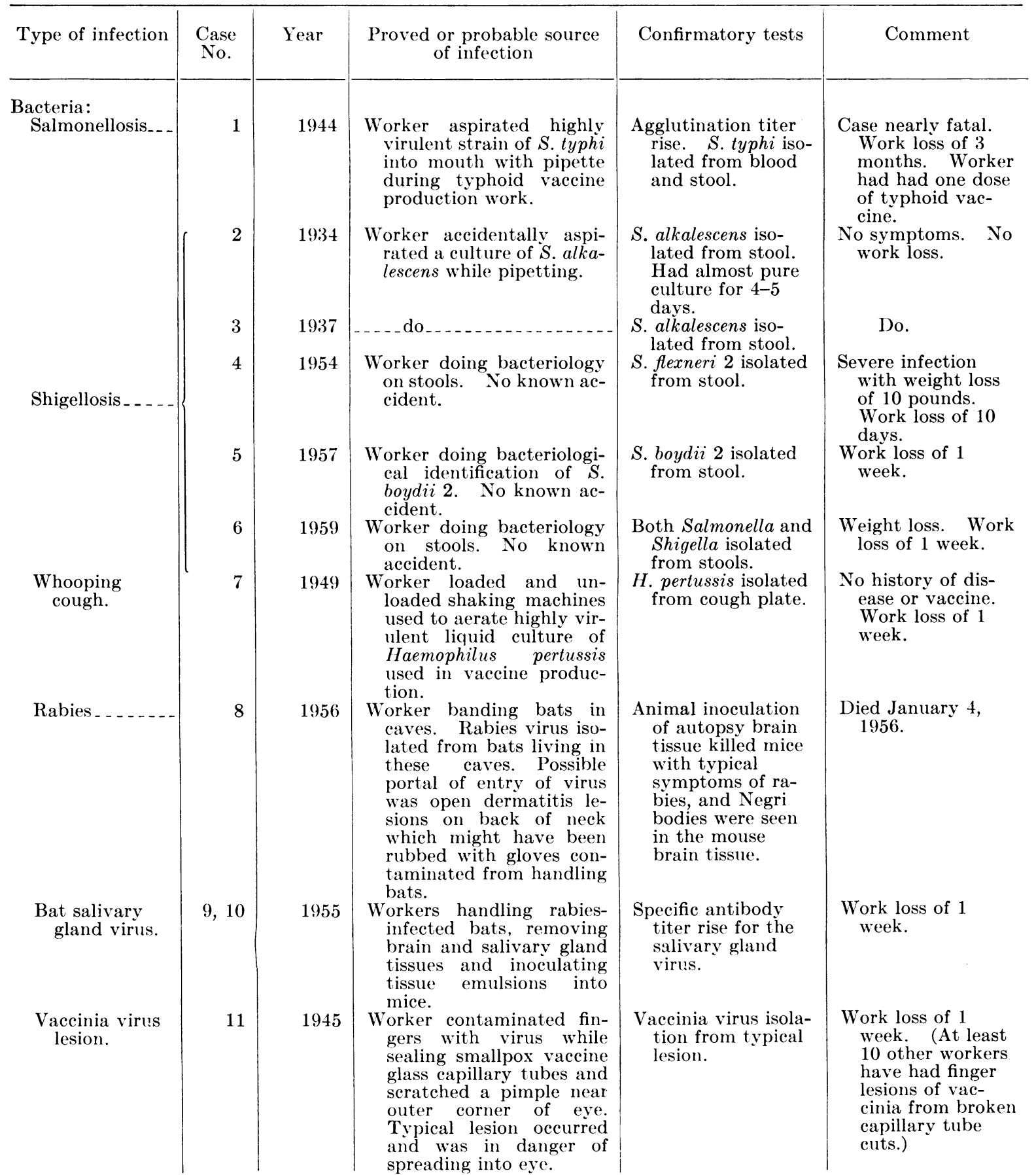




\section{Summary of laboratory-acquired infections in Texas State Department of Health, 1930-60 Continued}

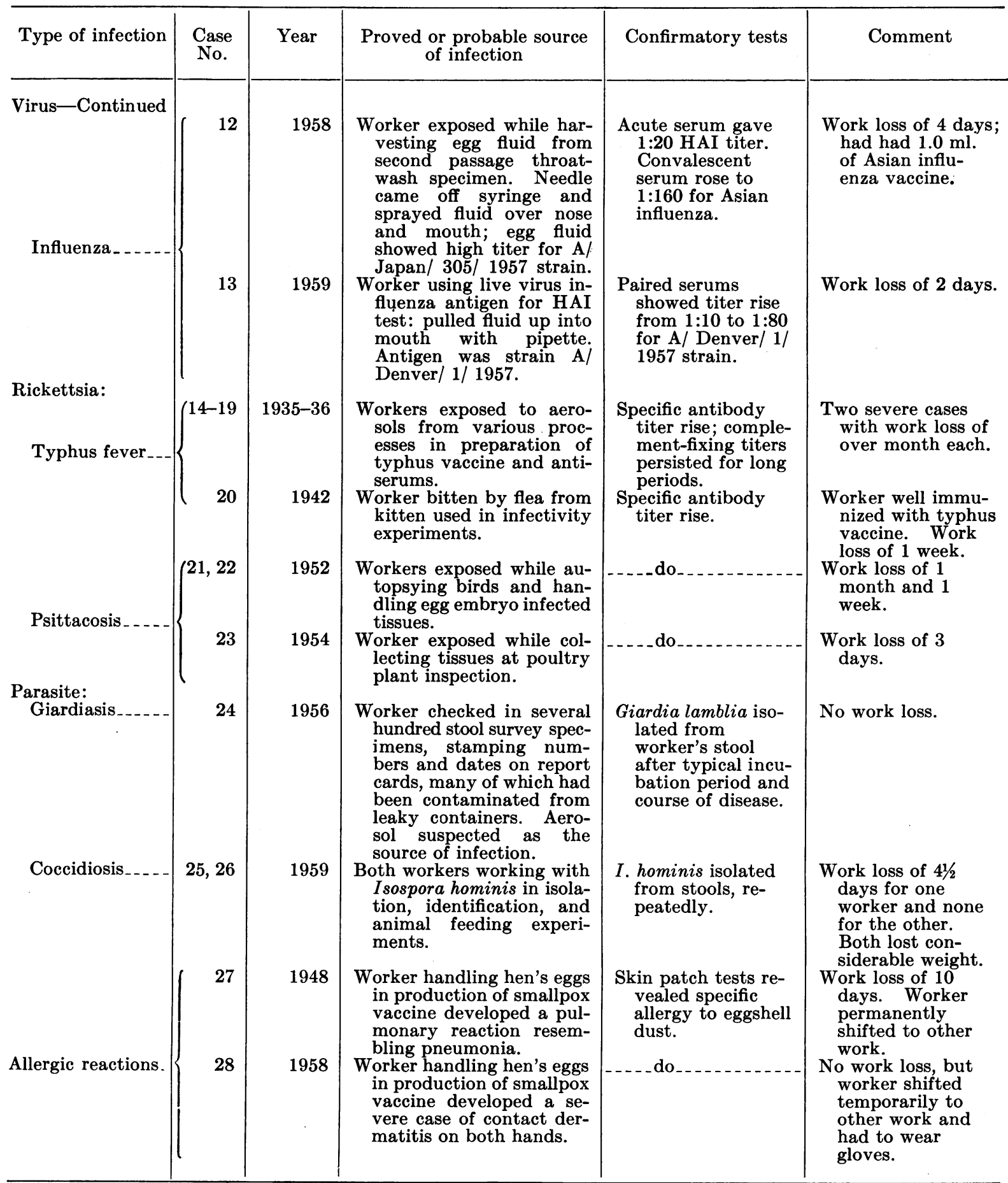

1 One infection acquired in the field (case No. 8). 
hazards associated with crowded laboratory workspace and animal quarters and inadequate equipment and safety devices. Serious accidents other than those which caused the infections, included nine severe cuts, two of which required surgical repair and hospitalization, three broken bones from falls on stairways or uneven floor surfaces, and six severe burns, one of which was a facial burn due to an ether explosion fire.

\section{New Laboratory Quarters}

With the findings of the early surveys as a stimulus and a guide, safety was a prime consideration in the design of the new laboratory quarters. Above all we wanted to segregate the work with highly infectious pathogens. We also wanted to avoid crowded work areas, to have adequate sterilization facilities, and to provide all practical safety devices.

In the new quarters the work with viruses and rickettsiae is conducted in a separate, specially designed building. The tuberculosis and mycological diagnostic work is done in a specially designed, isolated area. Workspace in every unit is adequate. Animal quarters include a quarantine room, feed storage room, areas and equipment for cage sterilization and washing, and an incinerator for disposal of infectious debris and animal bodies. Bacteriological safety cabinets were installed for work with pathogens. Eye-bath facilities and overhead showers are available near the acid-cleaning sinks for use in case of splash accidents.

A survey by the safety committee in 1960 , however, revealed that despite the careful attention given to isolation of work with infectious pathogens and provision of adequate workspace and safety devices, four cases of laboratoryacquired infections and one case of an allergic reaction occurred after the move into the new building (see table). Two accidents were directly responsible for three of these cases. Case No. 13 was due to accidental contamination of the mouth with infectious fluid with a pipette, and No. 25 and No. 26 came from accidental partial strangulation of a rabbit during a feeding experiment causing the animal to cough and spray the parasitic organism into the faces of two workers. These two cases of infection with the parasite Isospora hominis are of particular interest because apparently only 400 organisms used in the prepared capsule fed to the rabbit were sufficient to infect both workers at the same time (5).

Ten other accidents were noted in the 1960 survey, three of which could have resulted in infections. One of these involved a needle and syringe; another, breakage of an ampule containing a dried culture of Salmonella typhi; and a third, the bite of an infected animal. Other accidents included cuts or stabs from broken glassware and wood splinters. One of the wall cabinets filled with glassware fell on two workers (there were no injuries). One accident occurred in the laboratory warehouse. A worker dropped a bottle of sulfuric acid on a concrete floor, splashing the acid over his feet and legs. Prompt washing with large amounts of water and application of basic neutralizers prevented skin damage.

The 1960 survey revealed few hazards in the new building that could not be remedied. Such things as doorstops extending too far into passages, inadequate knee room under worktables, slick spots on floors due to heavy wax concentration, and wet glazed tile floors can be eliminated or the hazards minimized. Safe handling of potentially dangerous materials is a matter for diligent education and supervision.

\section{Safety Administration and Education}

Attention to the human element is recognized as one of the most important measures in preventing laboratory accidents and infections. It is essential that the individual worker be alert to the dangers that exist. He must feel responsible not only to himself but to others for developing and practicing safe techniques. Education and training of laboratory personnel toward these ends, we believe, is the most fruitful approach to safety in the laboratory.

In the Texas State Department of Health, general administrative rules and regulations governing laboratory practices are clearly set down. These concern the entrance and exit of materials into and from the laboratories; eating, drinking, and smoking in restricted areas; changes of clothing and showers; procedures to be followed in the event of an accident, includ- 
ing decontamination procedures; and entrance of visitors. Specific regulations cover procedures known to be particularly hazardous, such as tissue grinding or maceration, centrifuging of infectious materials, pipetting of infectious liquids, use of hypodermic syringes and needles, drying of pathogens and opening of dried culture ampules, handling of infected animals, and opening of diagnostic specimen containers. There are also regulations governing the handling of poisonous, corrosive, or explosive chemicals.

The Texas State Department of Health conducts an immunization program for all employees in "at-risk" work areas and makes periodic checks of immune status. For example, tuberculin skin testing is done annually on workers performing diagnostic tests for tuberculosis.

Supervisors of the laboratory divisions are responsible for orienting the new employees regarding the rules and regulations, for the general safety education of new employees, and for the enforcement of regulations covering particularly hazardous procedures. The safety education of the employee includes instruction in decontamination procedures to be used in the event of laboratory accidents involving infectious materials or dangerous chemicals. The manual prepared at Fort Detrick has been found to be a helpful reference on microbial decontamination procedures $(6)$.

\section{Safety in Animal Handling}

Safety in handling of laboratory animals from purchase and quarantine to final disposition is a major concern in the laboratory. Many of the naturally occurring infections of laboratory animals are directly transmissible to man, either through handling of animals or contact with nasal, fecal, or renal discharges, through bites of infected animals, or through contact with infected tissues of animals at autopsy. Perhaps the greatest danger is the inapparent infection that comes to light only when the animal is placed under stress.

To minimize the infection hazard as well as the economic loss from diseased animals, our animals are purchased from local dealers, and the establishments of these dealers are checked frequently. The only exception are the mice used for typhoid vaccine potency testing which are purchased from certain out-of-State dealers because of recurrent Salmonella infections in mouse colonies of local breeders.

All rabbits, guinea pigs, monkeys, and dogs coming into the laboratory are held in quarantine for 1 to 2 weeks before they are moved into permanent quarters. They are carefully checked for any sign of illness. The rabbits used for production of rabies vaccine, in particular, are carefully screened for extraneous infections during the quarantine period, since the brain tissue is used directly in the final vaccine.

The laboratory workers are instructed in safety techniques in the inoculation of infectious materials into animals and in the inspection of these animals after inoculation. Such precautions as the use of bacteriological safety hoods for inoculation of animals with tuberculosis specimens are routine practice. After inoculation these animals are held in an isolated unit in the animal quarters. All animals inoculated with viral and rickettsial specimens are also handled under safety hoods and are maintained in animal quarters within the virus building.

The laboratory animal caretakers are also instructed as to safety precautions to be observed in feeding, watering, and handling of animals inoculated with pathogens. They are taught how to sterilize and wash cages and dispose of such animals without hazard to their health. Cage debris and animal bodies are carried directly to the incinerator in closed containers.

\section{Conclusion}

Constant attention to the existence of laboratory hazards, orientation and education of new workers in laboratory safety procedures, continued emphasis on safety for old employees, and maintenance of protective immunization for "at-risk" workers, wherever possible, are measures the Texas State Department of Health is stressing in its efforts to reduce laboratory accidents and infections to a minimum. These are the measures recommended by the department's "watchdog" committee on laboratory safety, appointed to survey work hazards and suggest remedies. 


\section{REFERENCES}

(1) Sulkin, S. E., and Pike, R. M.: Survey of laboratory-acquired infections. Am. J. Pub. Health 41 : 768-780 (1951).

(2) Irons, J. V., et al.: The public health importance of bats. Texas Rep. Biol. \& Med. 15: 292-298 (1957).

(§) Clarke, D. H., and Casals, J.: Technique for hemagglutination and hemagglutination-inhibi- tion with arthropod borne viruses. Am. J. Trop. Med. \& Hyg. 7 : 561-573 (1958).

(4) Sulkin, S. E., Wallis, C., and Allen, R. : Relationship of bat salivary gland virus to St. Louis encephalitis group of viruses. Proc. Soc. Exper. Biol. \& Med. 93: 79-81 (1956).

(5) Henderson, H. E. : An outbreak of isosporiosis in a school for mental defectives. (In press.)

(6) Practical procedures for microbial decontamination. Frederick, Md., Fort Detrick, Safety Division, September 1956.

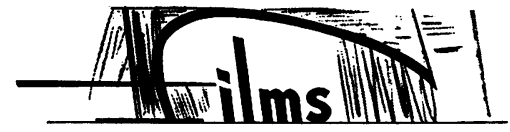

\section{Biology and Control of the Cockroach}

16-mm. motion picture, color, sound, 489

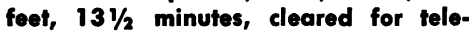
vision, 1960. (Order No. M-426.)

Audience: Stafe, county, and local sanitarians.

Designed to train sanitarians in recognition and control of the cockroach, the film also presents new insecticides for use against chlordane-resistant roaches.

For those who prefer a filmstrip as a teaching aid, No. F-91, under the same title, is available.

\section{Germfree Animals in Medical Research}

16-mm. motion picture, color, sound, 19 minutes, 1960. (Order No. M-430.)

Audience: Universities, medical schools, laboratories, and research instifutes.

The film demonstrates techniques used successfully at the National Institute of Allergy and Infectious Diseases, Public Health Service, to create a germfree environment, place in it a germfree animal, and maintain the animal without introducing contamination.

Studies underway using germfree animals include host-parasite rela- tionships, nonspecific host defense mechanisms, immunological studies, and role of micro-organisms in oral and dental diseases and in nutritional and metabolic processes.

\section{High-Temperature Short- Time Pasteurization: Inspection and Testing}

16-mm. motion picfure, color, sound, 907 feet, 25 minutes, 1960, cleared for television. (Order No. M-391.)

Audience: Milk sanitarians, authorities of sanitation policies and programs, sanitary engineers, health officers, undergraduate dairy technologists.

Designed for training inspection personnel in the procedures for testing the functioning and accuracy of high-temperature, short-time pasteurization controls according to the standard milk ordinance, this film supersedes the 1951 film, No. M-10a, of the same title.

\section{Leptospirosis}

16-mm. motion picture, color, sound, 596 feet, $16 \frac{1 / 2}{2}$ minutes, 1960, cleared for television. (Order No. M-329.)

Audience: Veferinarians, physicians, bacteriologists, public health personnel, and undergraduates.

The film is designed to alert physicians and professional personnel to the possibility of human infection, and to acquaint laboratory personnel with the identification, mode of transmission, and other aspects of leptospirosis. Phases of the disease are depicted.

\section{Management of the Leprosy Patient}

16-mm. motion picfure, color, sound, 698 feet, 19 minutes, 1960. (Order No. M-392.)

Audience: Nonprofessional, suifable for the general public as well as citizen groups. (Physicians are referred to the motion picture No. M-374, "Recognition of Leprosy," which deals with diagnosis.)

Depicting the procedures used at the Public Health Service hospital at Carville, La., in treating and rehabilitating its 260 patients, the film is intended as an aid in overcoming the nonacceptance by society of the discharged patient because of old superstitions and erroneous beliefs that leprosy is highly contagious.

These films are available on shortterm loan, United States only, from the Communicable Disease Center, Atlanta 22, Ga., Attention: Audiovisual. They can be purchased from United World Films, Inc., 1445 Park Avenus, New York 29, N.Y. 